\title{
STUDIES ON THE CULTURE OF A MARINE DIATOM
}

\author{
By C. P. Spencer \\ The Marine Biology Station, \\ University College of North Wales, Bangor
}

(From the Plymouth Laboratory)

(Text-figs. I-I6)

Little is known of the biochemistry of diatoms, although many workers have reported growth experiments with the unicellular algae of the marine phytoplankton. Experiments have often been performed without due regard for the appropriate control of physical and chemical conditions. Many reports contain only incomplete data of the growth under a given set of conditions, and it is often impossible to say whether the effects recorded are upon the growth rate, the total crop, or both. Other studies have been reported which included the addition of organic matter to cultures which were only uni-algal and not bacteria-free. At the present time even the mere maintenance of stock cultures of the marine unicellular algae is perforce an empirical matter. Results in replicate cultures often show gross differences in growth that are apparent on inspection by eye alone, and insufficient information is available regarding the nature of these variations in growth to allow the rational development of improved culture media. Due therefore to a lack of suitable techniques, most of the results available are difficult, if not impossible, to interpret in terms of the biochemical activities of the algae.

Quantitative measurements of the growth of bacterial cultures have been widely used by Hinshelwood, Monod and others (Hinshelwood, I946; Monod, I942). The technique may be limited in its application, for example in the elucidation of metabolic pathways by the permeability of the cell wall to intermediates, but such studies can furnish much valuable information. Investigations have shown that the growth of bacteria as measured by an increase in cell numbers or cell material generally obeys certain simple rules. The growth can thus be defined by a number of growth constants which reflect the physiological behaviour of the cells. Similar considerations should apply to the growth of any unicellular organism. Comparison of the growth constants under various conditions should therefore provide some information about the suitability of these conditions for culture work, allow the rational development of improved culture media, and make possible fuller interpretation of the results of growth experiments. 
It is normal practice at the moment to use natural sea water as a base for culture medium for the marine unicellular algae. This is usually enriched with further amounts of phosphate, nitrate and soil extract. The preliminary investigation reported in this paper has been restricted to experiments in medium of this type.

\section{Definition OF TERMS Used}

In this paper the terminology used by the previous workers on the kinetics of bacterial growth has been largely adopted. The nature of some of the growth phases obtained, however, is such as to lead to difficulties if the traditional nomenclature is followed. These exceptions will be discussed later as they

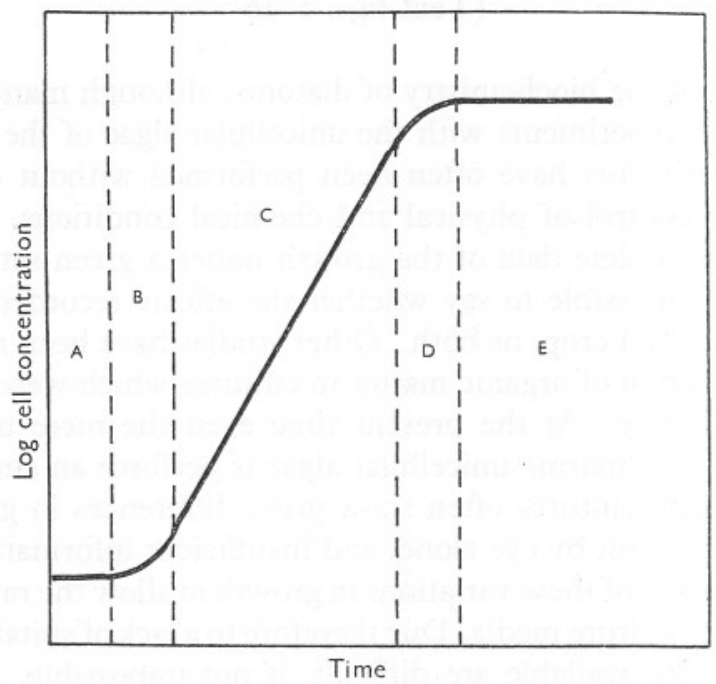

Fig. I. An idealized growth curve showing the five phases of growth. A, initial stationary phase; $\mathrm{B}$, phase of increasing growth rate; $\mathrm{C}$, exponential phase; $\mathrm{D}$, phase of decreasing growth rate; $\mathrm{E}$, final stationary phase.

arise. The various growth phases are best described in terms of an idealized growth, as shown in Fig. I. It is obvious that the growth may be expressed in terms of either the increase in cell numbers (cell concentration) or the increase of cellular material (cell density). Since the technique used for estimating growth measures cell concentration, in all that follows the term growth will be used to mean an increase in cell numbers per unit volume.

When cells of the test organism are inoculated into suitable culture medium cell division may or may not start at once. In the latter case there is usually an initial stationary period, during which no increase in cell concentration occurs, though there may be an increase in cell density. The initial stationary phase is followed by a phase of increasing growth rate when the rate of cell division increases with time up to a maximum value. The initial stationary 
phase and the phase of increasing growth rate are often considered together and called the 'lag phase'. The lag phase is followed by a phase of regular exponential growth, the cell concentration increasing with time in geometrical progression according to the equation:

$$
n=n_{0} e^{k t},
$$

where $n_{0}$ is the original cell concentration and $n$ the cell concentration at time $t$, $k$ being a constant. During this exponential growth the division rate of the cells remains constant. The extent of the exponential phase is limited by the utilization of nutrients or other modifications in the culture medium caused by the growth of the organism, and it finally leads to a phase of decreasing growth rate. During this phase the growth rate decreases with time until it becomes zero. This last phase is known as the final stationary phase.

It is convenient to depict growth graphically on a plot of $\log _{2} n$ (or in some cases $\log _{2} n / n_{0}$ ) against time. On a plot of this sort an increase of one unit on the ordinates corresponds to one cell division. The lag time is usually measured by a plot of $\log _{2} n / n_{0}$ and extrapolating to zero when the intercept on the time axis gives the lag time. The exponential growth may be characterized by the mean generation time or the time taken for the cell concentration to double. The total growth is the difference between the initial and the final (i.e. during the final stationary phase) cell concentration. These three constants, the lag time, the mean generation time and the total growth, largely characterize the growth obtained under a given set of cultural conditions.

\section{METHODS}

\section{Organism Used and Maintenance of Stock Cultures}

The diatom used in these studies was a bacteria-free strain of Nitzschia closterium (Ehrenberg) Wm. Smith forma minutissima Allen \& Nelson. The species was first isolated by Allen \& Nelson (I9IO) and has since been maintained at the Plymouth Laboratory in the Miquel sea-water medium of Allen \& Nelson. Unlike many other marine algae, this diatom will grow indefinitely in the absence of soil extract. Because of this, the organism was considered more suitable for the initial studies of the effect on growth of the basic physical and chemical factors than one needing the unknown factors of soil extract. A bacteria-free strain of the organism was obtained by treatment with penicillin and streptomycin as previously described (Spencer, I952).

Stocks of the organism were maintained by periodic aseptic subculture on solid media (see later for composition). After good growth was obtained, the cultures were removed from the light and stored in the dark at $2^{\circ} \mathrm{C}$. Such stored cultures show little loss of viability for periods of up to 6 weeks. Stocks were normally kept on slopes in rimless Pyrex boiling-tubes stoppered with 
cotton-wool and illuminated in a north window. The algal growth obtained on solid medium is sometimes somewhat mucilagenous and individual colonies may be quite hard. In neither culture is the growth conducive to even spreading by means of a wire loop. It has been found convenient to subculture the stocks by scraping selected growth off a slope with a wire loop and suspending, by agitation, in sterile sea water until the latter is just observably turbid. Loop-fulls of this suspension may then be spread evenly with a wire loop on the surface of a slope. The resulting growth then consists of numerous discrete colonies. The solid medium used will allow a good growth of many marine bacteria and its use for the maintenance of stocks is useful, since any gross bacterial contamination will at once show itself. The absence of obvious bacterial colonies is nevertheless no proof of sterility. Routine periodic checks of freedom from bacterial and other contamination were carried out by inoculation into a range of bacteriological media (Spencer, 1952) of I ml. samples of subcultures in liquid medium.

Passage through a subculture on solid media has a marked morphological effect on the cells. The original stock culture of the organism contained both the normal and the tri-radiate type of cells with a preponderance of the latter (Wilson, 1946). The first visible growth on solid media consisted entirely of naked cells, but normal cells appeared and soon predominated. On subculture to liquid medium, all naked cells disappeared and the culture consisted entirely of normal cells. After many serial subcultures in liquid media the tri-radiate form has not re-appeared. These observations seem in the main to confirm the findings of Barker (1935).

\section{Culture Media}

For reasons stated before, the present work has been confined to an examination of growth in media made up from natural sea water. Freshly collected off-shore water (International Hydrographical Station E. I) was filtered through a Whatman no. 3 filter-paper and then allowed to age by storage in the dark for about I month. This ageing process assists uniformity between various batches of media. Difficulty was often experienced due to the formation of a precipitate as a result of autoclaving. This precipitation may perhaps be due to several factors, but experience showed that by following the procedure outlined below it could nearly always be avoided. The water was initially collected and allowed to age in Pyrex glass bottles. Medium was made up with this aged sea water diluted to $75 \%$ with glass-distilled water to give a resultant salinity of c. $26 \%$. The sea water was enriched at this stage with $2.0 \mu \mathrm{g}$. \% manganese (as manganese chloride) and the nitrogen source (normally sodium nitrate) at the required concentration. It was then dispensed into the culture vessels in use, and after plugging with cotton-wool these were sterilized by autoclaving at $5 \mathrm{lb}$. pressure for $30 \mathrm{~min}$. After cooling and being allowed to re-equilibrate with the carbon dioxide of the air, the 
medium was further enriched by additions of $10.0 \mu \mathrm{g} . \%$ iron (as ferric citrate-citric acid: Rodhe, I948) and phosphate at the required concentration (usually as disodium hydrogen phosphate). These additions were made aseptically from sterile stock solutions of the required strength. In the initial experiments additional silica was added at this point. Experience, however, showed that this addition was without effect on growth at the population densities used. This is not surprising since it is certain that considerable solution of silica occurs during autoclaving (F. A. J. Armstrong, private communication). In all that follows the term 'basic medium' is used to indicate $75 \%$ sea water with additions of iron and manganese.

The solid medium used for the maintenance of stock cultures consisted of the basic medium (with additions of $\mathrm{I} \cdot 2 \mathrm{mg}$. \% nitrate-nitrogen and $0.3 \mathrm{mg} . \%$ phosphate-phosphorus) solidified with $\mathrm{I} \cdot 5 \mathrm{~g} . \%$ agar and further enriched with $0.5 \mathrm{~g} . \%$ peptone (Oxoid brand, bacteriological peptone). Some growth is obtained on solid media with nitrate nitrogen as the sole nitrogen source, but the addition of peptone causes more prolific growth. Better growth is obtained on media containing both peptone and nitrate than with either alone. Ammonium nitrogen seems to be equivalent to nitrate nitrogen for growth on solid media.

Analytical quality reagents were used throughout.

\section{Culture Apparatus}

Details of the culture apparatus used are shown in Fig. 2. For the quantitative experiments, the organism was cultured in $25 \times 150 \mathrm{~mm}$. rimless Pyrex boiling tubes. The cultures were aerated by means of a small-bore Pyrex tube which passed to the bottom of the culture tubes and was drawn out to a fine jet. It was found convenient for aseptic handling and for optical determinations of culture density to have the aerating tube held for its entire length against the side of the culture vessel. This was achieved by sealing about I in. of the top internal surface of the culture vessel to the aerating tube using 'Araldite' cement. The tubes were plugged with cotton-wool. A small guard filter containing cotton-wool was attached by rubber tubing to the aerating tube of each vessel. The open end of the guard filter containing cotton-wool was attached by rubber tubing to the aerating tube of each culture vessel. The open end of the guard filter was protected by a small inverted test-tube during autoclaving or storage before use.

The culture vessels were cleaned by prolonged scrubbing in hot soap and water followed by continual rinsing in cold tap water and finally by two rinses with hot distilled water. After much use the culture vessels often became coated with a greasy substance which was very resistant to the normal washing procedure. This could usually be removed by boiling the culture vessels in a soap-and-soda solution followed by prolonged rinsing in hot water.

The culture tubes were held in a rack and immersed in water to within I in. 
of their tops in a glass-sided tank. This was situated in a constant temperature room without natural light. The water on the bath was rapidly circulated and thermostatically controlled at any desired temperature with an accuracy of $\pm 0 \cdot 2^{\circ} \mathrm{C}$.

Compressed air was well washed by passage through two Henrichi gaswashing bottles and then filtered by passage through an aspirator completely filled with cotton-wool. This was frequently autoclaved. The sterile air was

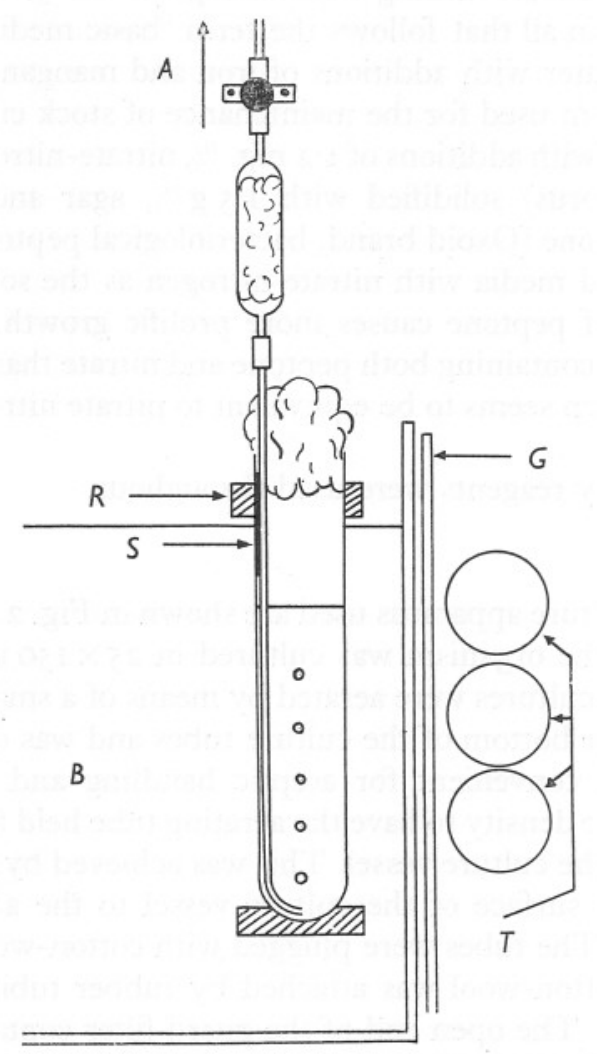

Fig. 2. Diagram of the culture apparatus used for the quantitative culture of $N$. closterium. $A$, to air supply; $B$, constant temperature bath; $G$, opal glass screen; $R$, rack; $S$, araldite seal; $T, 80 \mathrm{~W}$ fluorescent tubes.

then passed into a glass manifold which ran out over the culture vessels in the constant temperature bath. The outlets of the manifold were connected by rubber tubing to the individual guard tubes on each culture vessel. The supply of compressed air was controlled by a master pin valve and a screw clip on each manifold outlet. Air was bubbled through each tube at a constant rate of about $50 \mathrm{ml} . / \mathrm{min}$. 
Illumination was provided by three $80 \mathrm{~W} 5 \mathrm{ft}$. fluorescent tubes. These were fixed one above the other at one side of the glass tank and extended its whole length. The intensity of illumination of the cultures could be varied by inserting opal glass screens between the lights and the side of the tank.

No attempt has been made during the present studies to investigate systematically the effects of changing the lighting conditions. Examination of the emission spectrum of 'day-light' fluorescent tubes showed them to be poor in light in the red region of the spectrum. Since chlorophyll has an absorption band in this region it was thought advisable to include some red light in the illumination. This was done by using two $80 \mathrm{~W}$ 'day-light' tubes and one $80 \mathrm{~W}$ red fluorescent tube. Preliminary experiments showed that if the culture vessels in the constant temperature bath were placed at a distance of about 3 in. from the lamps they received an incident illumination of approximately 12,000 lux. It was shown that this intensity of illumination was such that decreasing it by $25 \%$ had no effect on growth up to cell densities equivalent to a limiting initial nitrate-nitrogen concentration of $\mathrm{I} \cdot 2 \mathrm{mg}$. $\%$. The degree of agitation provided by aeration proved to be sufficient to prevent mutual shading by the cells at the cell concentrations used. The conditions were therefore considered to be light saturated with respect to growth.

\section{Estimation of Growth}

Several previous workers have considered the use of optical-density measurements of algal cultures as a means of estimating growth (Rodhe, I948; Gross \& Koczy, I946; and Osterlind, I949). For the present studies a Harvey absorptiometer (Harvey, I948) has been modified to project a parallel beam of light through the culture. The optical density of cultures was read, using the culture vessels as cuvettes. These were inserted into the light path of the absorptiometer and held in a specially made Perspex cell containing water. This fitted into a V-shaped channel in the absorptiometer and was automatically aligned. The base of the cell contained a circular depression to hold the bottom of the culture tube, the removable lid to the cell having a circular hole of the same diameter as the culture tube. The depression and hole were made so that the culture vessel was held vertically. Access to the Perspex cell was by a coincident hole in the case of the absorptiometer, which could be covered by a sliding shutter when not occupied by a tube. Each culture vessel was marked so that it was placed in the Perspex cell in exactly the same position each time, with the aerating tube to the side and out of the way of the light path. The light path was cut down to a circular beam $6 \mathrm{~mm}$. in diameter by means of a stop on the incident light side of the Perspex cell. This served to minimize any disturbing effect from the curved surface of the culture vessel and eliminate interference with the light beam by the aerating tube.

To correct for individual differences in the culture vessels the following procedure was adopted for measuring the optical density of cultures. The 
Perspex cell containing water was used throughout as a fiduciary standard. The culture vessel containing the complete medium was placed in the absorptiometer and the small optical density $\left(E_{0}^{\prime}\right)$ due to the tube and contents measured. The medium was inoculated with cells and the optical density again determined $\left(E_{0}^{\prime \prime}\right)$, the difference between these two values giving the initial optical density of the culture $\left(E_{0}\right)$. The value of $E_{0}^{\prime}$ for each tube was subtracted from all subsequent optical density readings of the culture to give the true value of $E$ at time $t$.

Initial experiments largely confirmed the findings of earlier workers in that the optical density is approximately proportional to the number of cells per unit volume (cell concentration) up to an optical density of about $\mathrm{r} \cdot 0$. But, again as in the earlier work, it was found that there is no constant relationship from culture to culture between the optical density per unit thickness of culture and cell concentration. The relationship varies, amongst other things, with the physiological state of the cells and their content of chlorophyll. Preliminary experiments had demonstrated that a suspension of the organism shows no sharp absorption peaks in the visible when examined with a Unicam spectrophotometer. However, experience showed that the best results are obtained by using red filters (Chances OR I). Investigations with various cell suspensions of equal cell concentration showed that there is a considerable variation in the ratio between the loss of light due to scattering and the loss of light due to absorption. By varying the optical system it was found possible to arrange that the optical density as measured approximated to that due to absorption alone. This was done by using a small stop on the incident light side of the Perspex cell and a large stop which exposed the whole of the active area of the photocell on the transmitted light side of the Perspex cell. The Perspex cell was fitted in the absorptiometer as close as possible to the photocell. These conditions ensure that nearly all the light which is scattered at an angle of less than $90^{\circ}$ to the incident is received by the photocell. On the other hand, with the Perspex cell situated at some distance from the photocell and with a stop in the incident light the same size as that in the transmitted light path, all scattered light is lost and the optical density as measured includes the light lost by both absorption and scattering. The relationship between the optical density of a growing culture of $N$. closterium due to absorption and scattering, the optical density due to absorption alone, and the cell concentration is shown in Fig. 3.

It will be seen that a growth curve drawn from optical density measurements in the 'near' position approximates to that obtained by using cell concentrations. The rate of increase of this component of optical density is comparable to the rate of increase of cell concentration. This is not so with the curve drawn from the optical density measurements in the 'far' position. The relationship between the two optical density measurements and the cell concentration at various points during the growth is shown in Table I. 


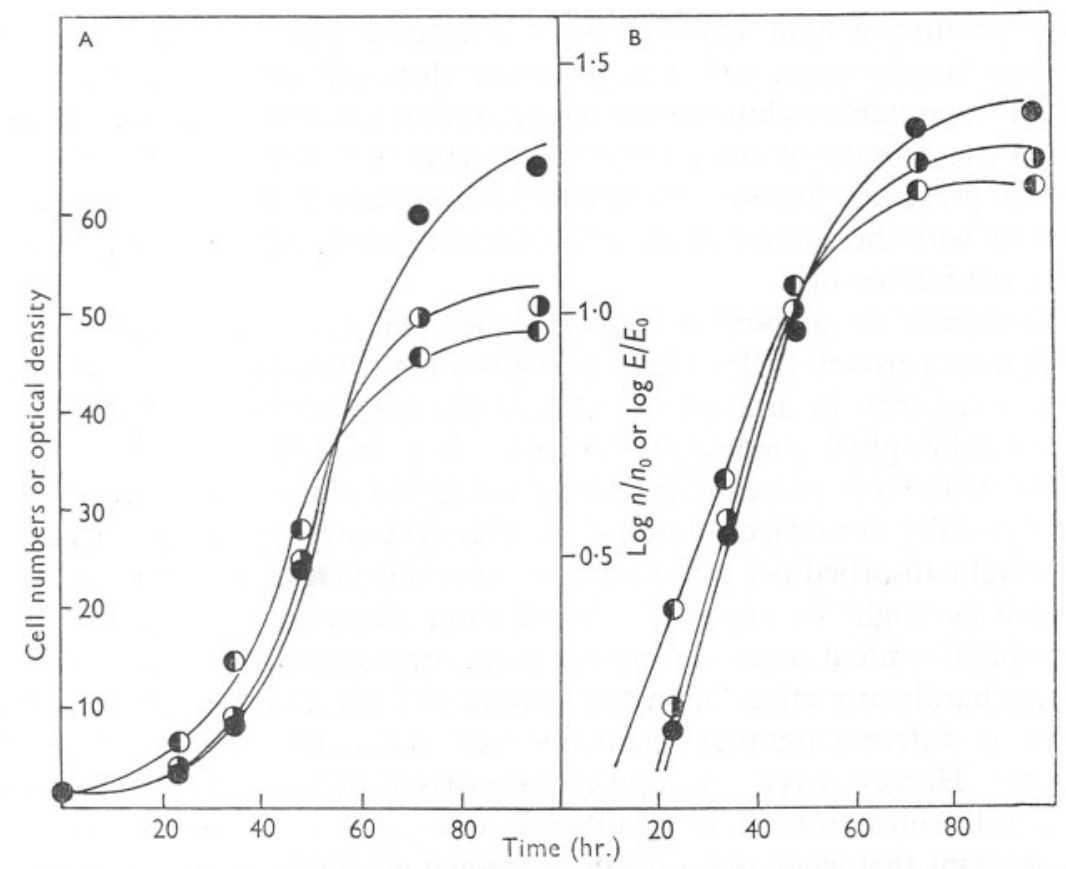

Fig. 3. The growth of a typical culture of $N$. closterium showing the growth curves obtained by using: (a) cell concentration, - - - - (b) optical density measurements in the 'near' position, - - - - ; (c) optical density measurements in the 'far' position, $-\mathbf{0}-\mathbf{0}-$. In A the ordinates represent arbitrary values of cell concentration and optical density calculated as follows: cell concentration, numbers per ml. $\times 1^{-5}$; optical density in the 'near' position, $E \times 2.5 \times 10^{2}$; optical density in the 'far' position, $E \times 3.7 \times 10$. Optical densities measured using Chances OR I filters. In B are given the corresponding logarithmic plots.

\section{TABle I. VARIATION IN THE LIGHT SCATTERED PER CELL AND THE LIGHT ABSORBED PER CELL THROUGHOUT THE GROWTH OF A CULTURE OF}

\section{NITZSCHIA CLOSTERIUM}

Ratio O.D. per $10^{6}$ cells per $\mathrm{ml}$.

$\begin{array}{lllllll}\quad \text { Optical system } & \circ \mathrm{hr} . & 23 \mathrm{hr} . & 34 \mathrm{hr} . & 48 \mathrm{hr} . & 72 \mathrm{hr} . & 96 \mathrm{hr} \text {. } \\ \begin{array}{lllll}\text { Optical density in 'near' posi- } \\ \text { tion (approximates to light }\end{array} & 0.040 & 0.046 & 0.044 & 0.042 & 0.035 & 0.032 \\ \text { absorbed) } & & & & & \\ \begin{array}{l}\text { Optical density in 'far' posi- } \\ \text { tion (approximates to light }\end{array} & 0.268 & 0.490 & 0.420 & 0.310 & 0.202 & 0.199\end{array}$

tion (approximates to light absorbed + light scattered)

The amount of light scattered per cell varies greatly throughout a growth cycle. It increases markedly during the commencement of exponential growth. Thereafter it declines steadily until the onset of the phase of decreasing growth rate when it exhibits a rapid decrease. The significance of measurements of O.D.(scattered light) must remain speculative. However, the variations 
in the amount of light scattered per cell suggests that this optical property depends largely upon cell density rather than cell concentration. Unfortunately no suitable techniques for the determination of dry weight are available due to the salinity of the culture media and the small amount of cellular material present. However, the amount of light scattered per cell does at least correlate with the volume of the protoplasmic content of the cells as observed under the microscope.

In contrast, the amount of light absorbed per cell is much more constant throughout a growth cycle. This is perhaps somewhat surprising since it might be expected that the amount of red light absorbed would be greatly affected by the chlorophyll content of the cells. It is known that the chlorophyll content of the cells decreases markedly during the phase of decreasing growth rate especially in nitrogen-limiting cultures (Harvey, I953). Some variation in the light absorbed per cell does occur over this period, but the effect is not as great as might be expected. In addition, considerable increases in the chlorophyll content occur during the initial stationary phase, but these seem to have hardly any effect upon the amount of light absorbed per cell. Cells grown at differing lighting intensities have markedly different chlorophyll contents (Harvey, 1953) and optical comparison of such cell suspensions of equal cell concentration give different O.D.(absorbed light) values. Nevertheless, it seems that when the cultures are grown in identical lighting conditions and, providing iron is in ample supply (Rodhe, 1948), the variation in the component $0 . D_{\text {(absorbed light) }}$ per cell due to variations in the chlorophyll content are largely outweighed by other more constant factors. With the organism used, the overall size of the frustule seems to vary little throughout a growth cycle. Possibly it is this part of the cell which is the major factor controlling O.D.(absorbed light).

To summarize, measurements of O.D.(absorbed light) provide a method of comparing the cell concentrations of cultures of the organism used. Comparisons must be made between cultures in the same physiological states, grown in identical lighting conditions, and cultured with an adequate supply of iron. It is perhaps unwise to apply the method to any but bacteria-free cultures of the organism because of possible interference by bacterial growth. The cells of the culture must be evenly distributed and this necessitates continual agitation throughout growth, since microscopical examination shows that very considerable agitation is needed to break up all the cell clusters in a culture which has grown undisturbed for any time. The formation of precipitates in the culture medium must be avoided. This may be difficult since precipitation which is undetectable to the naked eye can occur in the course of the growth of a culture in the media used.

It must be emphasized that these considerations apply only to cultures of $N$. closterium and may not be applicable to algal cultures in general. It is known that the chlorophyll per cell decreases markedly during the phase of 
decreasing growth rate, especially in nitrogen-limiting cultures (Harvey, I953). During this phase, and the subsequent exhaustion phase, the optical density increases more slowly than the cell concentration, and in consequence there is no strict proportionality between the optical density and the cell concentration. During these phases of growth variations of up to $23 \%$ have been observed in the cell concentration corresponding to a given optical density.

\section{GROWTH EXPERIMENTS}

\section{The Exponential Growth Phase}

It has been found possible using the cultural conditions described to obtain regular exponential growth of $N$. closterium, and under these conditions the mean generation time has remained remarkably constant over many subcultures.

\section{Effect of Changed Cultural Condition}

Before regular exponential growth can be obtained, the cells must be adapted to the physical and chemical conditions of the medium. Any change in these factors causes a period of irregular growth which may extend over many generations. Several factors, a change of which causes a period of irregular growth, have been investigated and will be discussed below. Fig. 4 shows some typical examples of irregular growth compared with the regular exponential growth obtained with cells adapted to the cultural conditions.

Curve I shows the typical regular exponential growth exhibited by cells adapted to the cultural conditions by previous growth in the normal basic medium enriched with additions of $0.6 \mathrm{mg} . \%$ nitrate-nitrogen and $0.6 \mathrm{mg} . \%$ phosphate-phosphorus per litre and grown with continuous illumination and aeration at $19^{\circ} \mathrm{C}$. Curve II shows the nature of the growth obtained on subculture of these cells at $9^{\circ} \mathrm{C}$. under otherwise identical conditions. Curve III is the growth obtained when cells adapted to the conditions of curve I are subcultured into medium containing $0.3 \mathrm{mg}$. \% phosphate-phosphorus per litre, other conditions being unchanged. A similar irregular growth obtained on changing the cultural conditions is shown in curve IV. In this case cells grown on solid media were subcultured to the normal basic media under conditions identical to those under which the growth in curve I was obtained.

The irregular growth obtained on changing certain cultural conditions is generally characterized by periods during which no cell division occurs or of a much reduced division rate, alternating with periods of division at a greater rate than exhibited by adapted cells under the same conditions. That the phenomenon is essentially a lack of adaptation to changed cultural conditions is indicated by the observation that continued subculture in the new conditions finally leads to regular exponential growth being established. 

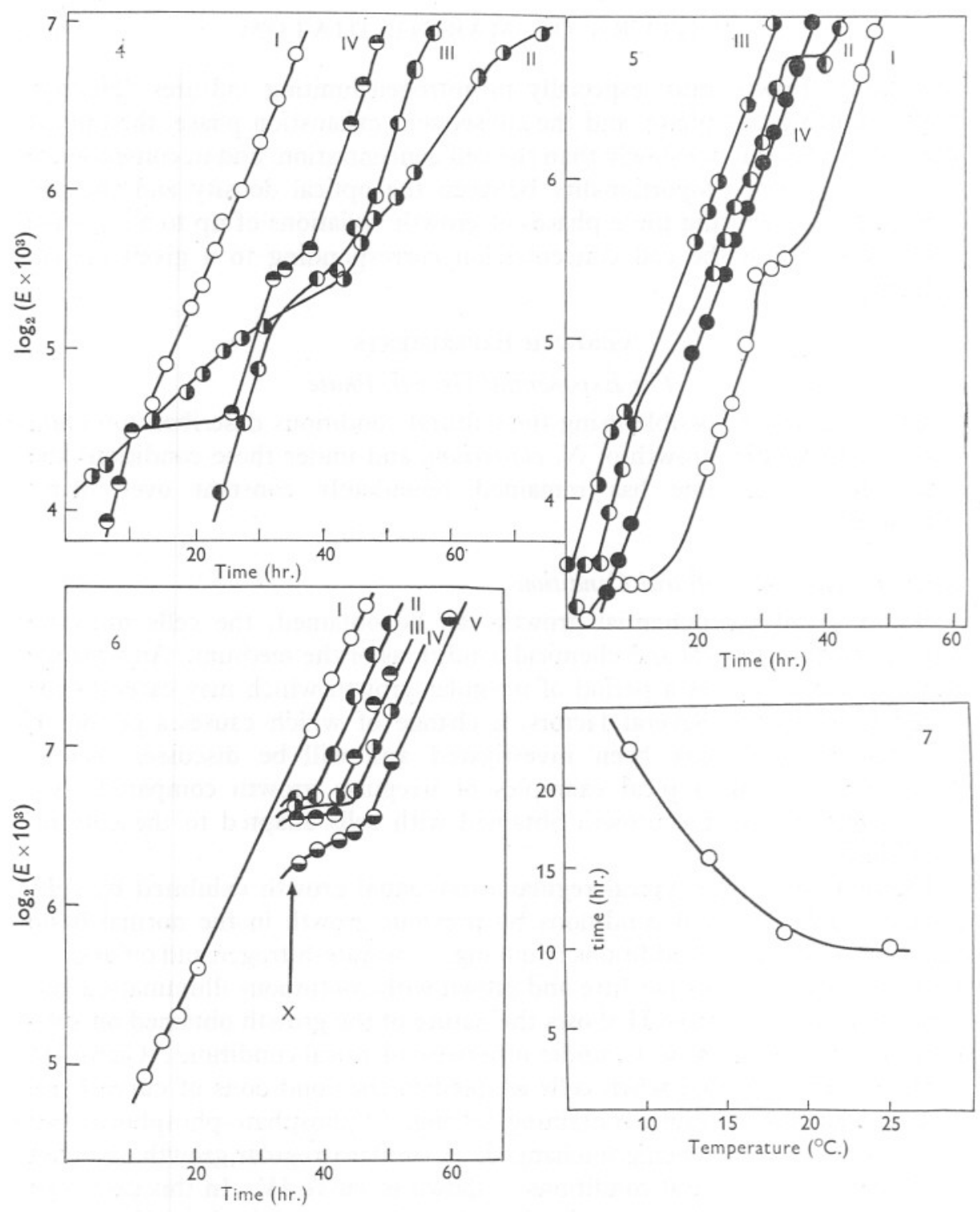

Fig. 4. Typical growth curves obtained with $N$. closterium by adapted (curve I) and by unadapted cells (curves II, III and IV). For details of culture conditions see text.

Fig. 5. The adaptation to changed cultural conditions. Parent culture grown on usual solid medium at room temperature in natural light from a north window and transferred to basic liquid medium with additions of $\mathrm{r} \cdot 2 \mathrm{mg}$. \% nitrate-nitrogen and $0.3 \mathrm{mg} . \%$ phosphate-phosphorus at $19^{\circ} \mathrm{C}$. with continuous illumination and aeration. Curves I-IV, second to fifth subcultures respectively.

Fig. 6. Replicate cultures in the basic medium with additions of $\mathrm{r} \cdot 2 \mathrm{mg}$. $\%$ nitrate-nitrogen and $0.3 \mathrm{mg}$. \% phosphate-phosphorus, grown to logarithmic phase at $19^{\circ} \mathrm{C}$. with continuous illumination and aeration. After $34 \mathrm{hr}$. growth $(X)$ cultures subjected to various periods of darkness and then re-illuminated.

Fig. 7. Variation of the mean generation time with temperature of cultures grown in the basic medium with additions of $0.6 \mathrm{mg} . \%$ nitrate-nitrogen and $0.3 \mathrm{mg}$. \% phosphatephosphorus with aeration and continuous illumination. 
Fig. 5 shows the gradual adaptation to changed cultural conditions of cells which have been grown on solid medium in a north window in natural light at room temperature on subculture to basic liquid medium at $19^{\circ} \mathrm{C}$. with constant illumination and aeration. The first subculture under the new conditions is not shown in the diagram. In this case five successive subcultures (together representing 20 to 25 divisions) had to be made before the cells became adapted to their new environment. This was one of the longest adaptation periods observed; sometimes as little as four divisions were sufficient to obtain regular exponential growth. In general the length of the adaptation period varies directly with the magnitude of the change in the cultural conditions. Once adaptation has been achieved the regularity of the exponential growth depends only upon the constancy of the prevailing cultural conditions.

When a culture of the organism is growing exponentially, the growth rate represents the resultant velocity of the whole series of reactions whereby cell substances are synthesized. The growth rate corresponds to the overall rate of a steady state system, the velocity constant of this system depending upon the resultant of the velocity constants of all the reactions involved. During such growth all the properties of the cell are constant, and any change in the cultural conditions may necessitate a change in the concentration of intermediates and enzymes. This re-organization may prevent regular exponential growth from being re-established immediately. It is possible that the irregular growths obtained are explicable in these terms.

The periods of very rapid growth alternating with periods of growth at a much reduced rate that are characteristic of unadapted cells suggest that the processes of cell division are in some way inhibited, whereas the synthesis of cell material may continue. In consequence, when cell division can occur it does so at a more rapid rate than normally by utilizing intermediates that have accumulated during the period of low division rate. The periods of rapid growth are soon succeeded by growth at the normal or at a suboptimal rate, presumably as the factors controlling cell division again come into play.

\section{Effect of Dark Periods}

The lighting conditions were such that the cells can be considered lightsaturated with respect to growth. Under these conditions, periods of darkness cause an almost complete cessation of growth (Fig. 6). In the typical experiment shown re-illumination after up to $\mathrm{I} 2 \mathrm{-h}$. periods of darkness allows an immediate resumption of regular exponential growth at the same rate as before. The experiment shown in Fig. 6 was performed with quintriplicate cultures all inoculated at the same time. The variations in cell concentrations after $36 \mathrm{hr}$. in cultures I, II, III and IV are in the same ratio as, and explicable by, variations in the size of the inocula. This is not so with curve V, the growth of which was apparently retarded by some unknown factor. It will be 
seen that during the period in the dark this culture exhibited a slow but marked growth until the cell concentration reached a value comparable with that of the other cultures before the illumination was stopped. It would seem that if growth is held back by inhibitory factors or deficiencies which primarily affect metabolic channels other than those involved in photosynthesis, some cell division can occur in subsequent dark periods. Presumably this occurs by utilization of 'excess' carbon skeletons formed during prior periods of photosynthesis.

It is interesting to compare these results with those obtained in similar experiments by Rodhe (I948). He observed a decrease in the optical density of cultures during dark periods and an initial 'growth' on re-illumination at a very rapid rate. This gradually dropped to a much slower rate. In the experiments reported in this paper no such effects during or after dark periods have been observed. There must have been respiratory losses during the dark periods, and the reason that these did not show up in optical-density measurements during the present studies can only mean that the optical density as measured is a function of cell concentration rather than cell density. On the other hand, it seems that Rodhe's optical-density measurements must have been a function of cell density. If this were so, the more rapid 'growth' he observed after dark periods could represent an initial rapid synthesis of cell material only, the division rate of the cells remaining unaffected.

\section{Effect of Temperature}

The exponential growth rate depends upon the temperature. The results of a preliminary investigation on the variation of growth rate with incubation temperature is shown in Fig. 7. The mean generation time falls rapidly with increasing temperature, reaching a minimum for these cultural conditions at about $20^{\circ} \mathrm{C}$. Further increases in temperature have little effect on growth rate but no inhibitory effect is observed up to $25^{\circ} \mathrm{C}$. All inocula for the experiments summarized in Fig. 7 were taken from a parent culture grown in media of identical composition at $19^{\circ} \mathrm{C}$. A $10^{\circ} \mathrm{C}$. change in temperature causes a period of irregular exponential growth which lasts for about four divisions. No adaptation period is required on subculture from 19 to $14{ }^{\circ}$ or $25^{\circ} \mathrm{C}$. Between 9 and $20^{\circ} \mathrm{C}$. the Arrhenius Law is approximately obeyed as might be expected. It is to be expected that further increase in temperature above $25^{\circ} \mathrm{C}$. will lead to a rapid increase in the mean generation time followed by a complete cessation of growth resulting from denaturation of proteins and disorganization of the cell.

\section{Effect of Carbon Dioxide Tension}

For regular exponential growth to continue, chemical as well as physical conditions must be constant. Under normal cultural conditions the concentration of nutrients is not constant due to their continued utilization during 
growth, and division is stopped soon after the supply of one or more nutrients becomes exhausted. In the absence of aeration, the rate of diffusion of carbon dioxide into sea-water medium at a $\mathrm{pH}$ of about 8.6 is sufficiently slow to cause the supply of carbon dioxide for photosynthesis frequently to become limiting. This is clearly shown in Fig. 8 in which typical growths obtained with and without aeration are shown. It will be seen that, in the absence of aeration, the growth rate is soon affected and quickly drops almost to zero. In unaerated cultures the $\mathrm{pH}$ may rise to a value of 9.4 or higher before growth is stopped. The inhibition of growth in the unaerated culture is immediately reversed when aeration is recommenced.

It is apparent that aeration is necessary in cultures of the cell concentration used if the supply of available carbon for photosynthesis is not to drop below growth saturating levels. However, at least up to cell concentrations corresponding to a limiting nutrient concentration of $\mathrm{r} .0 \mathrm{mg} . \%$ nitrate-nitrogen, it seems that bubbling with air will keep the concentration of available carbon sufficiently high to maintain regular exponential growth. A limiting nutrient concentration of $\mathrm{I} \cdot 0 \mathrm{mg}$. \% nitrate-nitrogen corresponds to a cell concentration of about $\mathrm{I} 5 \times 10^{6}$ cells per $\mathrm{ml}$. $\mathrm{pH}$ values in the region of 9.0 often occur in the later stages of regular exponential growth in aerated cultures. It is impossible to say from these results whether growth in non-aerated cultures is primarily inhibited by a shortage of available carbon or by the adverse effect of high $\mathrm{pH}$. There is no evidence to suggest that at these growth rates and cell concentrations it is necessary to increase the partial pressure of carbon dioxide in the aerating gas to prevent this nutrient from becoming rate limiting. However, utilization of available carbon is sufficiently rapid to cause the $\mathrm{pH}$ to rise, and it may be advisable sometimes to use a higher partial pressure of carbon dioxide to obtain greater control of $\mathrm{pH}$.

\section{Effect of Other Nutrients}

For maximum growth rate the concentration of the nutrients other than carbon dioxide must be such that all enzymic and other active centres are saturated with their respective substrates. No effect on the initial growth rate can be observed by reducing the nitrate-nitrogen concentrations or the phosphate-phosphorus concentrations down to Io $\mu$ g. \%. Similarly, increases in the concentration of iron or manganese have no effect on the exponential growth rate. Consequently, it seems that the concentrations of these substances normally used are sufficient to saturate all active centres. It would be expected that, as the exponential growth rate becomes dependent upon a nutrient concentration at lower values, a hyperbolic relationship will exist between nutrient concentration and growth rate. However, special methods will be needed to determine the growth rate at these very low nutrient concentrations, since the total growth under these conditions is insufficient 
to permit an accurate determination of growth rate by the techniques used in the present studies.

\section{The Total Crop}

\section{The Onset of the Phase of Decreasing Growth Rate}

The total growth in any medium will be limited by the onset of one of several conditions. Amongst the factors which may cause cessation of exponential growth and the onset of the phase of decreasing growth rate, Monod (I949) lists the following: (i) the exhaustion of an essential nutrient, (ii) the accumulation of inhibitory metabolic products, and (iii) changes in the ionic equilibrium of the medium caused by the growth of the organism, for example $\mathrm{pH}$. The culture conditions outlined above include an adequate supply of carbon in photosynthetically available form and thereby some degree of control of $\mathrm{pH}$ and there is no evidence that the supply of iron or manganese is limiting. The total growth should therefore be controlled only by the initial concentration of either nitrate or phosphate. Fig. 9 gives the latter part of a typical growth curve, showing the gradually decreasing growth rate typical of the exhaustion of a nutrient. The culture in this experiment was adapted to the prevailing conditions. It may be demonstrated that the decline of exponential growth is due to exhaustion of nitrate or phosphate since further additions of the limiting nutrient allow a resumption of growth. In this particular case the limiting nutrient was nitrate, but similar curves may be obtained in phosphate-limiting cultures. It will be seen that the growth rate gradually decreases but does not finally become zero. The subsequent slow regular increase in the optical density of such cultures continues for a considerable time and has been followed for as long as $72 \mathrm{hr}$. after the onset of this phase. Cell counts have been conducted on cultures exhibiting this phenomenon, and the slow increase in optical density indeed represents a continued slow division. The rate of cell division during this phase depends to some extent upon the cell concentration, there being a tendency for it to be greater with higher cell concentrations.

This slow regular increase of cell concentration after the phase of decreasing growth rate may be due to either the continual addition to the media of limiting nutrient via the aerating gas (e.g. ammonia), or to autolysis of senile cells regenerating limiting nutrient in a form available to the remaining viable cells. Because of this slow cell division it is considered undesirable to call this final phase the stationary phase. It will therefore be referred to as the exhaustion phase.

\section{Adaptation to Increased Limiting Nutrient Concentration}

In experiments in which the growth of the diatom has been followed in cultures containing an adequate and constant amount of phosphate and varying amounts of nitrate another form of adaptation to changed cultural 

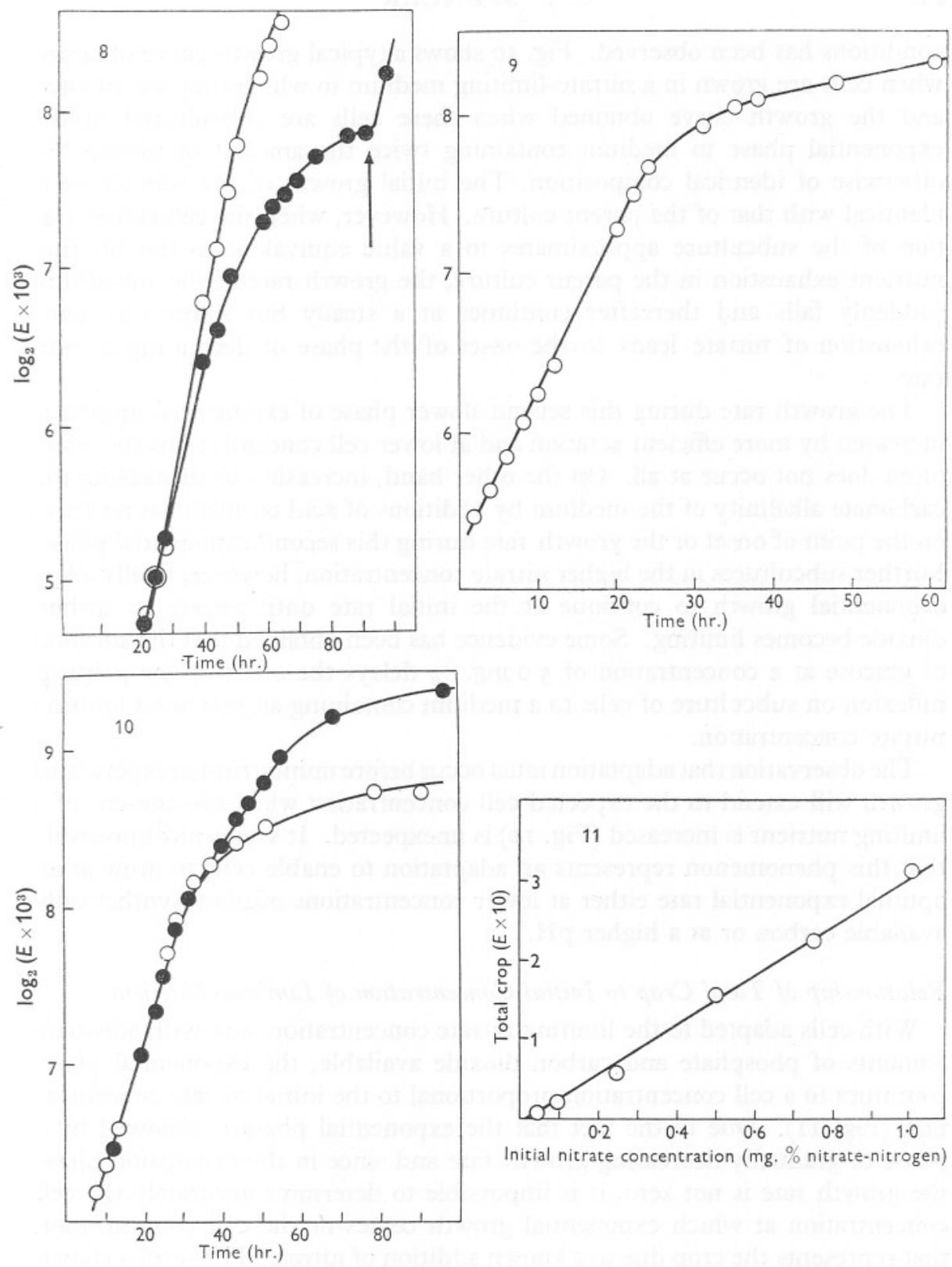

Initial nitrate concentration ( $\mathrm{mg}$. \% nitrate-nitrogen)

Fig. 8. Growth of $N$. closterium in the basic medium with additions of $\mathrm{I} \cdot 2 \mathrm{mg}$. $\%$ nitratenitrogen and $0.3 \mathrm{mg}$. \% phosphate-phosphorus with continuous illumination at $19^{\circ} \mathrm{C}$. $-\mathrm{O}-\mathrm{O}-$, culture aerated; - - unaerated. Arrow indicates aeration restarted.

Fig. 9. Growth in basic medium with additions of $0.6 \mathrm{mg}$. $\%$ nitrate-nitrogen and $0.3 \mathrm{mg}$. $\%$ phosphate-phosphorus with continuous illumination and aeration at $19^{\circ} \mathrm{C}$. showing the decrease in growth-rate caused by nitrate exhaustion.

Fig. Io. Growth in basic medium with additions of $0.3 \mathrm{mg} . \%$ phosphate-phosphorus with continuous illumination and aeration at $19^{\circ} \mathrm{C}$., with varying amounts of nitrate as limiting nutrient. - $-\mathrm{O}-$, growth of parent culture with $0.6 \mathrm{mg} . \%$ nitrate-nitrogen as limiting nutrient. - - growth of subculture with $\mathrm{I} \cdot 2 \mathrm{mg}$. $\%$ nitrate-nitrogen as limiting nutrient.

Fig. Ir. The variation in the total crop when grown in the basic medium with additions of $0.3 \mathrm{mg} . \%$ phosphate-phosphorus at $19^{\circ} \mathrm{C}$. with continuous illumination and aeration and with varying initial amounts of nitrate as the limiting nutrient. 
conditions has been observed. Fig. Io shows a typical growth curve obtained when cells are grown in a nitrate-limiting medium to which they are adapted and the growth curve obtained when these cells are subcultured in the exponential phase to medium containing twice the amount of nitrate but otherwise of identical composition. The initial growth of the subculture is identical with that of the parent culture. However, when the cell concentration of the subculture approximates to a value equivalent to the limiting nutrient exhaustion in the parent culture, the growth rate of the subculture suddenly falls and thereafter continues at a steady but lower rate until exhaustion of nitrate leads to the onset of the phase of decreasing growth rate.

The growth rate during this second slower phase of exponential growth is increased by more efficient aeration and at lower cell concentrations the effect often does not occur at all. On the other hand, increasing or decreasing the carbonate alkalinity of the medium by additions of acid or alkali has no effect on the point of onset or the growth rate during this second exponential phase. Further subcultures in the higher nitrate concentration, however, finally allow exponential growth to continue at the initial rate until nitrate or carbon dioxide becomes limiting. Some evidence has been obtained that the addition of glucose at a concentration of $5.0 \mathrm{mg}$. \% delays the onset of the point of inflexion on subculture of cells to a medium containing an increased limiting nitrate concentration.

The observation that adaptation must occur before uninterrupted exponential growth will extend to the expected cell concentration when the amount of a limiting nutrient is increased (Fig. IO) is unexpected. It seems most probable that this phenomenon represents an adaptation to enable cells to grow at an optimal exponential rate either at lower concentrations of photosynthetically available carbon or at a higher $\mathrm{pH}$.

\section{Relationship of Total Crop to Initial Concentration of Limiting Nutrient}

With cells adapted to the limiting nitrate concentration, and with adequate amounts of phosphate and carbon dioxide available, the exponential phase continues to a cell concentration proportional to the initial nitrate concentration (Fig. II). Due to the fact that the exponential phase is followed by a phase of gradually decreasing growth rate and since in the exhaustion phase the growth rate is not zero, it is impossible to determine accurately the cell concentration at which exponential growth ceases or the cell concentration that represents the crop due to a known addition of nitrate. The results shown in Fig. II are expressed in terms of an arbitrary value for the total crop. This has been defined as the cell concentration at the intercept when the exponential growth and the exhaustion phase are extrapolated to meet. Corrections must also be applied for the amount of available nitrogen added with the inoculum and the amount in the sea water used for making up the media. Providing this 
is done the crop is directly proportional to the initial concentration of the limiting nutrient. It is independent of the growth rate and of the inoculum size.

The results described above are for nitrate-limiting cultures. If the concentration of phosphate is made limiting analogous results are obtained with respect to the relationship between total crop and initial concentration of the limiting nutrient. In general, the total crop produced by a given limiting concentration of phosphate-phosphorus is equivalent to the total crop given by ten times this amount of nitrate-nitrogen.

\section{The Initial Phases of Growth}

\section{Effect of Limiting Nutrient Exhaustion}

Providing a sufficiently large inoculum is used, cells subcultured from the exponential phase into fresh medium of identical composition immediately continue growth at the same rate. In contrast, cells which are subcultured from the exhaustion phase do not grow immediately but exhibit an initial stationary phase. Fig. I2 shows the growth of inocula subcultured (a) from the exponential phase, $(b)$ from the early exhaustion phase, and $(c)$ after storage in the exhaustion phase for 4 days. The growth curves show an increasing lag time (as measured by the intercept of exponential growth on the time axis) related to the state of exhaustion of the parent culture. In addition, cells which have been stored in the exhaustion phase for several days show an initial phase of slow growth between the initial stationary phase and the onset of growth at the optimum exponential rate. Consequently, if lag time for such cultures is measured as above it includes a period of 'apparent lag' during which some cell division is occurring.

The variation of lag time with the condition of the cells of the inoculum is shown in Fig. I4. The upper part of the figure shows the growth curve of the parent culture which was inoculated with nitrate-exhausted cells. The lower part of the figure shows the lag times observed in daughter cultures in medium of the same composition inoculated at intervals with samples from the parent culture. The cells in each sample were sedimented by centrifuging and resuspended in fresh medium to avoid carrying over any old culture medium with the inocula. The size of each inoculum was adjusted so that each daughter culture initially had approximately equal cell concentrations.

Cells subcultured during the initial stationary phase of the parent culture show a decreasing lag, but this does not become zero until the cells of the parent culture have been growing for some hours. Throughout the exponential phase of growth cells show no lag on subculture, but the lag time rapidly increases as the cells of the inoculum pass into the phase of decreasing growth rate. The lag continues to increase rapidly for the first part of the exhaustion phase. The rate of increase in lag time then declines, and after about $30 \mathrm{hr}$. in the exhaustion phase its rate of increase reaches a steady value. 
The length of the lag period is clearly a function of the previous history of the cells and the long lags produced when the cells of the inoculum have been stored in the exhaustion phase for a long time must presumably be associated with a large number of reactions. Included in these must be the restoration of deficiencies caused by exhaustion of the limiting nutrient. There is considerable evidence to show that algal cells exhibit cell division after complete limiting nutrient utilization with the production of 'deficient' cells (Ketchum, I939;
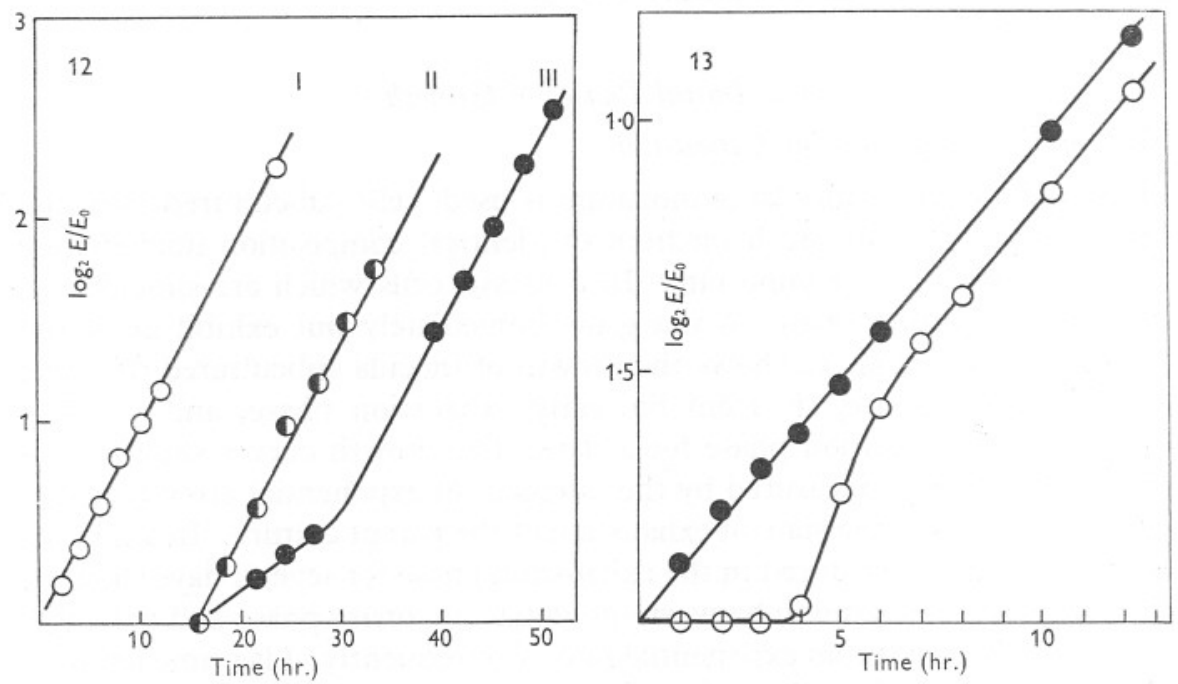

Fig. I2. Initial growth of $N$. closterium in the basic medium with additions of $0.6 \mathrm{mg} . \%$ nitrate-nitrogen and $0.3 \mathrm{mg} . \%$ phosphate-phosphorus at $19^{\circ} \mathrm{C}$. with continuous illumination and aeration. The cells of the inocula were adapted to these conditions by previous culture in the same media. The inoculum was of cells (I) from the exponential growth phase, (II) from the early exhaustion phase, (III) held with continuous illumination and aeration at $19^{\circ} \mathrm{C}$. for 5 days in the exhaustion phase.

Fig. I3. Initial growth in the basic medium with additions of $0.6 \mathrm{mg}$. $\%$ nitrate-nitrogen and $0.3 \mathrm{mg} . \%$ phosphate-phosphorus at $19^{\circ} \mathrm{C}$. with continuous illumination and aeration on subculture to fresh medium. - - large inoculum. - $-\mathrm{-}-$, small inoculum. The cells of the inocula were adapted to the cultural conditions by previous subculture.

Harvey, 1953). Comparison of measurements of growth by O.D.(absorbed light) and O.D.(absorbed light+scattered light) in the early phases of growth correlate well with the assumption that the initial stationary period consists of an increase in cell density, but not cell concentration.

The initial stages of suboptimal growth obtained after long storage in the exhaustion phase (Fig. I2) might be caused by a proportion of the cells being capable of division at suboptimal rates. The magnitude of the effect tends to increase with increasing age of the inoculum as would be expected if this were so. The addition with the inoculum of a number of totally non-viable cells would not produce this type of growth. 


\section{Effect of Inoculum Size on Initial Growth}

Cells subcultured during the exponential phase of growth show no lag if a sufficiently large inoculum is used. However, if smaller inocula are used a short lag is sometimes produced (Fig. I3). Close examination of the initial growth of subcultures using small inocula shows that the true division lag is greater than that obtained by extrapolating the normal exponential growth

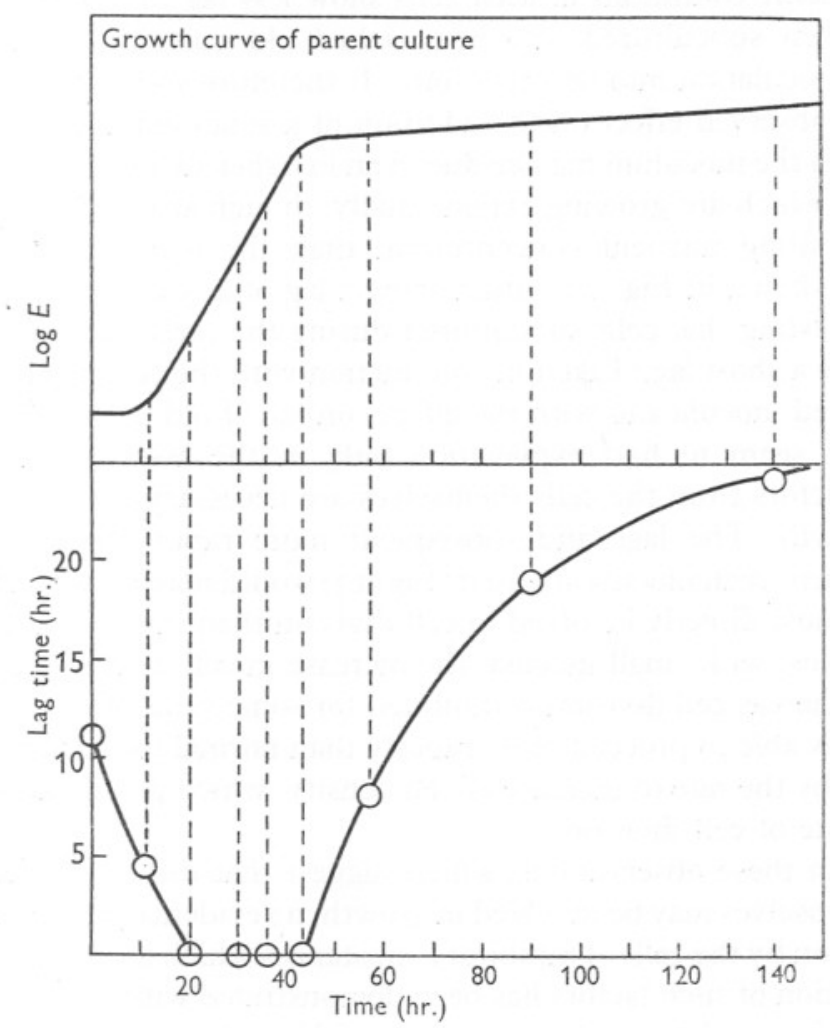

Fig. I4. Variation of the lag time (in the basic medium with additions of $0.6 \mathrm{mg} . \%$ nitratenitrogen and $0.3 \mathrm{mg} . \%$ phosphate-phosphorus at $19^{\circ} \mathrm{C}$. with continuous illumination and aeration) of cells of $N$. closterium with the age of the inoculum. The cells of all inocula were adapted to the cultural conditions by previous subculture.

to $E / E_{0}=\mathrm{I}$. This is due to an initial period of more rapid growth, as shown in Fig. I3.

All the results on the determination of lag reported above were obtained by using inocula of cells separated from the old culture medium by centrifuging. The more normal method of subculture is to transfer a few $\mathrm{ml}$. of the parent culture to the new media and some old culture medium is therefore added with the cells of the inoculum. Comparison of the lag times observed when old culture medium was or was not transferred with the cells of the inoculum has 
shown no appreciable difference between the subsequent lags and growths produced when exhausted cells were used as an inoculum. If the subsequent lags and growths obtained using small inocula on subculturing cells from exponential growth to fresh medium and into re-enriched cell-free culture medium taken from an exponential culture are compared, somewhat irregular results are obtained. Nevertheless, these results do give a strong indication that under some conditions at least cells show less lag (of the type shown in Fig. 13) when subcultured into re-enriched old culture media than they exhibit on inoculation into new medium. It therefore seems possible that the lack of any observed effect on the addition of a small amount of old culture medium with the inoculum may be due to an insufficient amount being carried over. Cells which are growing exponentially, though at a reduced rate due to a higher limiting nutrient concentration than the one to which they are adapted (as shown in Fig. I0), often show a lag of $4-5 \mathrm{hr}$.

It is interesting that cells subcultured during the early part of exponential growth show a short lag. Taken in conjunction with the results obtained with different-sized inocula and with the effects on lag of old culture media, these observations seem to find explanation only in the assumption that some diffusable factors from the cells themselves are necessary for optimum exponential growth. The lags and subsequent more rapid initial growth rate observed when small inocula are used (Fig. I3) would make it appear that these factors are most directly involved in cell division than in the synthesis of cell material. Thus, with small inocula, the increase in cell density may continue normally, whereas cell division is inhibited for some time. When cell division can start, it is able to proceed more rapidly than normal for a short time until it is limited by the rate of increase of cell density, which presumably normally limits the rate of cell division.

Apart from these observations, which suggest that diffusable factors from the cells themselves may be involved in growth, no evidence has been found for the production by the cells of inhibitory substances which tend to limit growth. The production of such factors has been demonstrated with Chlorella by Pratt (1940) and his associates and for a species of Nitzschia by Denffer (1948). It remains possible that the 'adaptation' of Nitzschia cells to an increased concentration of a limiting nutrient may involve an adaptation to a higher concentration of a diffusable inhibitory factor, produced by the cells themselves.

\section{Lags Induced by Varying the Initial Phosphate Concentration}

All the lags considered up to now are exhibited by cells adapted to the initial nutrient concentration of the medium. Subculture to widely different nitrate-nitrogen concentrations of nitrate-exhausted cells has no effect on the lag times produced. However, if exhausted cells which have been grown in phosphate-limiting media are subcultured to new medium with an increased phosphate concentration longer lag times are produced (Fig. I5). It will be 
seen that the lag time increases with increasing phosphate concentration up to about a fourfold increase. Thereafter further increases in the initial phosphate concentration have little effect. Additions of phosphate in excess of I. O mg. $\%$ phosphate-phosphorus usually cause precipitation to occur. In some cases the initial growth in high phosphate concentrations is irregular.

A preliminary investigation of the phosphate exchange occurring during the long lag phase produced if phosphate deficient cells are subcultured into high phosphate concentrations shows that a complicated situation exists. The
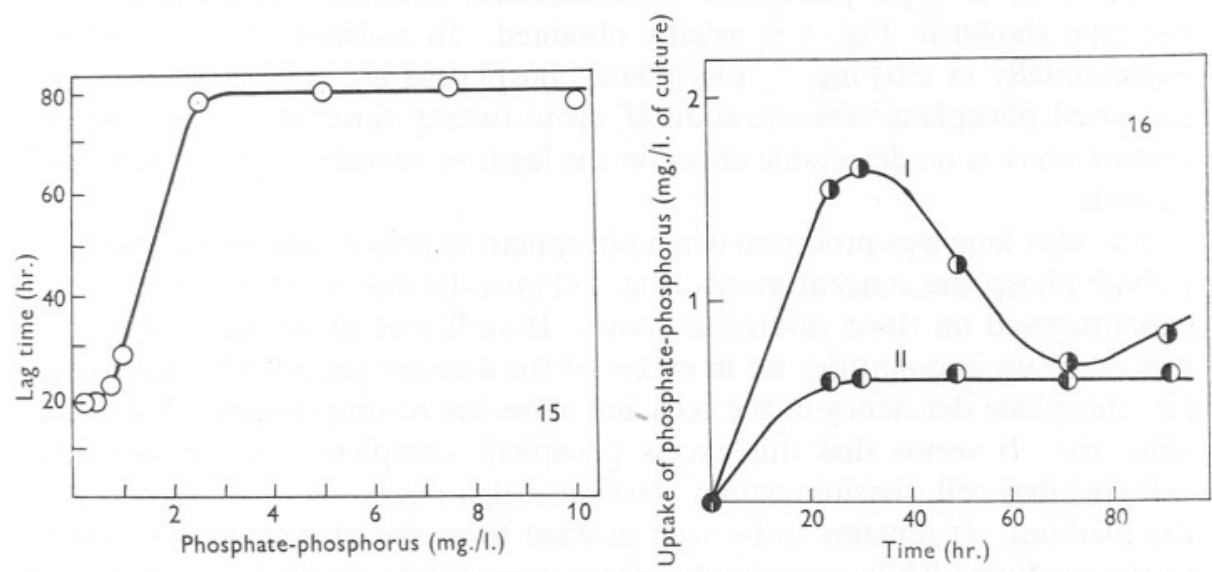

Fig. 15. Variation in the lag time of cells of $N$. closterium when grown in a medium containing $\mathrm{I} .2 \mathrm{mg} . \%$ nitrate-nitrogen and $0.05 \mathrm{mg} . \%$ phosphate-phosphorus at $\mathrm{I} 9^{\circ} \mathrm{C}$. with continuous illumination and aeration and subcultured from the exhaustion phase under the same conditions of lighting, temperature and aeration into medium containing identical amounts of nitrate and varying amounts of phosphate.

Fig. I6. Uptake of phosphate by two cultures of equal cell concentration inoculated with cells from the exhaustion phase of a phosphorus-limiting culture grown in basic medium containing I. $20 \mathrm{mg}$. \% nitrate-nitrogen and $0.06 \mathrm{mg} . \%$ phosphate-phosphorus. Curve I, basic medium with additions of $\mathrm{r} \cdot 20 \mathrm{mg}$. \% nitrate-nitrogen and $0.24 \mathrm{mg}$. \% phosphate-phosphorus. Curve II, basic medium with the same addition of nitrate and $0.062 \mathrm{mg}$. \% phosphate-phosphorus. Culture held at $19^{\circ} \mathrm{C}$. with continuous illumination and aeration. Phosphorus estimations conducted on suitable samples after removal of the cells by centrifuging.

inorganic phosphate in the medium was estimated by Harvey's method (I948). The culture containing $0.062 \mathrm{mg}$. \% phosphate-phosphorus took up practically the whole of this during the lag phase. A slight increase of the phosphate in the medium occurred after about I $60 \mathrm{hr}$. when the culture was in the exhaustion phase. This is presumably due to autolysis. The cells subcultured in $0.24 \mathrm{mg}$. $\%$ phosphate-phosphorus took up $0.16 \mathrm{mg}$. $/ 100 \mathrm{ml}$. of culture in the first $30 \mathrm{hr}$. Growth did not start in this culture until after nearly $90 \mathrm{hr}$., during which time about $0.105 \mathrm{mg}$./ I00 $\mathrm{ml}$. of the phosphorus originally taken up by the cells reappeared in the medium. When growth finally started in this culture 


\section{P. SPENCER}

the phosphorus content of the cells was therefore approximately the same as at the end of the lag phase in the cells subcultured to a lower phosphate concentration. Phosphate uptake recommenced in the culture in high phosphate as soon as growth started and continued until at $\mathrm{I} 60 \mathrm{hr}$. the whole of the phosphate had been taken up.

The prolonged lag produced on subculture to high phosphate concentrations is restricted to exhausted cells grown in a limiting amount of phosphate. If the exhausted cells have been grown in a limiting amount of nitrate and subcultured to high phosphate concentration, irregular initial growth of the type shown in Fig. 3 is usually obtained. In contrast, if cells growing exponentially in $0.05 \mathrm{mg}$. \% phosphate-phosphorus are subcultured into an increased phosphate concentration of up to twenty times that of the parent culture there is no detectable effect on the lag time or subsequent exponential growth.

The very long lags produced when phosphate-deficient cells are subcultured to high phosphate concentrations (Fig. I5) must be due to other factors being superimposed on those discussed above. If sufficient phosphate is supplied it is taken up in quantities far in excess of the amount required to make good the phosphate deficiency of the cells and allow the resumption of cell division (Fig. I6). It seems that this excess phosphate completely disorganizes the cell and that cell division cannot start until this excess has been returned to the medium. It remains to be seen in what form the phosphate is returned to the medium; labile organic phosphate compounds would be estimated as inorganic phosphate by the methods used.

\section{DisCUSSION}

The techniques developed during the present studies have made possible quantitative measurements of the growth of cultures of Nitzschia closterium forma minutissima. Regular exponential growth can be obtained which within certain limits is independent of the initial concentrations of the main nutrients and which varies with temperature according to the Arrhenius Law. The total crop produced is directly proportional to the initial concentration of a limiting nutrient and is independent of the growth rate. Control of experimental conditions has made possible a high degree of quantitative repeatability from culture to culture.

The fact that growth can be obtained which obeys a simple law suggests that under the defined conditions the basic medium used is suitable for quantitative growth studies. It is possible to predict accurately and control the rate of exponential growth under a given set of conditions and to control its extent by varying the initial concentration of a nutrient known to be limiting. The lag exhibited by an inoculum may be predicted from a knowledge of the previous history of the cells. 
On the other hand, in sea-water medium, the limits within which such studies are possible are rather narrow. Due mainly to difficulties in the supply of photosynthetically available carbon, the culture used must not increase above a rather low cell concentration. Even so, in cultures aerated with air the $\mathrm{pH}$ rises rapidly during optimal exponential growth. This is not ideal and some way of controlling the $\mathrm{pH}$ would be advantageous. This is especially important since for many purposes it is desirable to work at higher cell concentrations. The use of a higher partial pressure of carbon dioxide in the aerating gas may in any case be necessary with higher cell concentrations, and an attempt should also be made to develop a medium, suitable for marine algae, that is buffered by a component not utilized during growth. This will necessitate changes in the major ionic constituents since the high concentration of calcium makes sea water a very inflexible basis for media.

Similar factors may produce troublesome precipitation during the growth of cultures. This precipitation is not obvious to the naked eye, but shows itself by anomalous optical-density readings and often in sudden fluctuations in the $\mathrm{pH}$ of the culture. No way has been found of controlling this type of precipitation, and its occurrence has led to many cultures having to be rejected. Similarly, sea water is often difficult to sterilize by autoclaving due to precipitation occurring. Filtration techniques for sterilization have not been widely investigated, but it seems probable that, owing to the very low concentration of many ions in sea water, such techniques may lead to difficulties resulting from exchange phenomena and adsorption. The procedure used in the present studies, however, of diluting the sea water before autoclaving, mitigates the precipitation. A preliminary survey (Miss D. Ballantine, private communication) shows that many marine unicellular algae will tolerate this decreased salinity and the technique may be generally applicable.

It is difficult to obtain uniformity from one batch of sea water to the next. The 'ageing' process assists qualitative uniformity but it may produce widely different quantitative compositions, due, for example, to the release of available nitrogen by the bacterial decomposition of organic matter. When working at low cell concentrations these increases are large compared with the small amounts of nutrient added.

This work was performed at the Plymouth Laboratory of the Marine Biological Association. I should like to express my thanks to the Director, Mr F. S. Russell, F.R.S., for making freely available all the facilities of the laboratory; to all the staff for their helpfulness, and especially to Dr Mary Parke and Mr F. A. J. Armstrong, and to the latter for carrying out the phosphate estimations. Finally, it is a great pleasure to thank Dr H. W. Harvey, F.R.S., for introducing me to the field, for advice in the construction of the absorptiometer, and for his continued interest and many stimulating discussions. 


\section{SUMMARY}

Techniques are described for the culture of a bacteria-free strain of Nitzschia closterium forma minutissima under carefully controlled conditions. An investigation has been made of the absorption and scattering of light by cultures of the organism and a technique developed which enables an absorptiometric method to be used for measuring the growth of cultures.

Using the techniques described, the nature of the growth of the diatom has been studied in media made up by the addition to sea water of nutrient salts and trace elements. These studies have defined the limits within which such media may be used for quantitative growth studies and have indicated the limitations imposed on growth studies by media of this type.

\section{REFERENCES}

Allen, E. J. \& Nelson, E. W., I9Io. On the artificial culture of marine plankton organisms. F. Mar. biol. Ass. U.K., Vol. 8, pp. 42I-74.

BARKER, H. A., I935. Photosynthesis in diatoms. Arch. Mikrobiol., Bd. 6, pp. I4I-56. DeNFFER, D. Von, I948. A growth inhibitor in ageing cultures of diatomeae. Biol. Zbl., Vol. 67, pp. 7-13.

Gross, F. \& Koczy, F. F., I946. Photometric measurements of the growth of phytoplankton cultures. Medd. oceanogr. Inst. Göteborg, Ser. B, Bd. 5, no. 2, pp. I-I8.

HARVEY, H. W., I948. The estimation of phosphorus and total phosphorus in sea water. F. Mar. biol. Ass. U.K., Vol. 27, pp. 337-59.

- 1953. Synthesis of organic nitrogen and chlorophyll by Nitzschia closterium. 7. Mar. biol. Ass. U.K., Vol. 31, pp. 477-87.

Hinshelwood, C. N., 1946. The Chemical Kinetics of the Bacterial Cell. 284 pp. Oxford.

Ketchum, B. H., I939. The development and restoration of deficiencies in the phosphorus and nitrogen composition of unicellular plants. F. cell. comp. Physiol., Vol. I3, pp. 373-8I.

MonoD, J., I942. Recherches sur la croissance des cultures bacteriennes. 2 II pp. Paris.

— I949. The growth of bacterial cultures. Ann. Rev. Microbiol., Vol. 3, pp. $371-94$.

Osterlind, S., I949. Growth conditions of Scenedesmus quadricauda with special reference to the inorganic carbon sources. Symb. bot. upsaliens., $\mathrm{x}$, iii.

PRATT, R., I940. Influence of the size of the inoculum on the growth of Chlorella vulgaris in freshly prepared culture media. Amer. F. Bot., Vol. 27, pp. 52-6.

RoDHE, W., I948. Environmental requirements of fresh water plankton algae. Symb. bot. upsaliens., $\mathrm{x}, \mathrm{i}$.

SPENCER, C. P., I952. On the use of antibiotics for isolating bacteria-free cultures of marine phytoplankton organisms. F. Mar. biol. Ass. U.K., Vol. 31, pp. 97-I06.

WILson, D. P., I946. The triradiate and other forms of Nitzschia closterium (Ehrenberg) Wm. Smith, forma minutissima of Allen \& Nelson. 7. Mar. biol. Ass. U.K., Vol. 26, pp. 235-270. 